\title{
Epidemiology of Cutaneous Leishmaniasis Outbreak, Waziristan, Pakistan
}

\section{Mubashir Hussain, Shahzad Munir, Taj Ali Khan, Abdullah Khan, Sultan Ayaz, Muhammad Ameen Jamal, Irfan Ahmed, Sohail Aziz, Noha Watany, Mohamed Kasbari}

Author affiliations: Kohat University of Science and Technology, Kohat, Pakistan (M. Hussain, S. Munir, T.A. Khan, A. Khan); Abdul Wali Khan University, Mardan, Pakistan (S. Ayaz); Yunnan Agricultural University, Kunming, China (S. Munir, M.A. Jamal, I. Ahmed); Khyber Medical University, Peshawar, Pakistan (S. Aziz); US Naval Medical Research Unit 3, Cairo, Egypt (N. Watany); French Agency for Health and Safety, Maisons-Alfort, France (M. Kasbari)

DOI: https://doi.org/10.3201/eid2401.170358

During 2013-2015, prevalence of cutaneous leishmaniasis in war-affected Waziristan areas was $3.61 \%$ by PCR. Youths (1-15 years of age) were more susceptible. Internal transcribed spacer $1 \mathrm{PCR}$ followed by restriction fragment length polymorphism analysis identified Leishmania tropica in 215 samples and Leishmania major in 6 samples.

$\mathrm{C}$ utaneous leishmaniasis (CL), the most widespread form of leishmaniasis, caused by Leishmania tropica and $L$. major $(1,2)$, has emerged as an endemic disease in Khyber Pakhtunkhwa, Pakistan (2-5), owing to frequent movement of internally displaced persons (IDPs) from Waziristan in response to surgical strikes and military operations against terrorists by Pakistani armed forces. Keeping in view the impact of the frequent outbreaks of CL in settled areas, we studied the prevalence of CL in war-affected North and South Waziristan, with the help of health department and local government authorities.

We surveyed 7,548 persons from the different endemic areas and collected samples from ulcerating skin lesions from 538 suspected CL patients, 244 in North Waziristan and 294 in South Waziristan, during April 2013-January 2015. To sort out the reservoir, we captured 72 rodents from different locations in Waziristan, such as around houses, in cornfields, and in wild plantations surrounding the houses of CL patients, and analyzed liver and spleen samples by PCR. In addition, we collected sand flies from within $1.5 \mathrm{~km}$ of CL patients' houses for molecular analysis (6). We determined the prevalence rate of $\mathrm{CL}$ by a formula described previously (7) and performed statistical analyses using statistical software SAS Enterprise Guide (version 4.2; SAS
Institute, Cary, NC, USA) by univariate analysis of variance with statistical significance at $\mathrm{p}<0.05$.

Prevalence according to sex was consistent with previous findings, indicating that $\mathrm{CL}$ infections were more prone to develop in males (Table) because of more social activity and interaction with IDPs, whereas females always remain covered because of Islamic rules and thus are less prone to sand fly bites. Agewise, we observed a higher prevalence rate in children $0-15$ years of age $(1.61 \%)$ compared with other age groups. Sand flies and rodents were also collected from different endemic villages; none of the trapped rodent samples tested positive for leishmaniasis, but samples from sand flies from 2 endemic villages of North Waziristan (Razmak and Shewa) and 1 endemic village of South Waziristan (Sreykhoray) tested positive by kinetoplast DNA PCR. Samples collected from domestic animals (sheep, goat, cattle, donkey, dogs, mules) were negative for leishmaniasis.

For this report, we performed internal transcribed spacer 1 PCR followed by restriction fragment length polymorphism analysis for identification of different species of Leishmania. For North Waziristan, we observed $63.0 \%$ of L. tropica and $8 \%$ of L. major specific bands by this analysis. Similarly, restriction fragment length polymorphism analysis of South Waziristan showed $54 \%$ L. tropica and $4 \%$ L. major specific bands. No L. infantum-positive cases were found in any human or animal (dog) samples. Moreover, different species of Phlebotomus and Sergentomya sand fly genera were identified in both North and South Waziristan; P. sergenti was the most abundant species, followed by $P$. papatasi. We reported leishmaniasis infection in 6 female P. sergenti sand flies. P. papatasi is also susceptible to carry L. tropica and is widely distributed in different parts of Pakistan, including Khyber Pakhtunkhwa Province (8). A previous team had reported L. infantum in 2 army personnel deployed in Waziristan, (9) but the present detailed study ruled out its presence.

We conclude that CL is prevalent in Waziristan and new cases are increasing day by day. The present study also confirms that L. tropica is the causative agent of $\mathrm{CL}$ in Waziristan. This study also confirmed that anthroponotic CL caused by L. tropica is the main causative agent of CL in Waziristan. All the patients whose specimens tested positive for L. major had a history of traveling to zoonotic CL endemic areas of Mezar Sharif (Afghanistan) and Sindh and Balochistan (Pakistan) (10). Because of limited access in the study area for security reasons, sampling could not be performed in other endemic parts of Waziristan, so further molecular epidemiologic studies on animal reservoirs and sand flies should be conducted in wider areas of Waziristan, including neighboring tribal and settled areas, to map the complete distribution of the disease. 
Table. Areawise prevalence of $\mathrm{CL}$ in Waziristan, Pakistan, by microscopy and PCR

\begin{tabular}{|c|c|c|c|c|c|}
\hline \multirow[b]{2}{*}{ Area } & \multirow[b]{2}{*}{ No. tested } & \multicolumn{2}{|c|}{ CL-positive samples, no. ${ }^{*}$} & \multicolumn{2}{|c|}{ CL prevalence, $\%$} \\
\hline & & Microscopy & PCR & Microscopy & PCR \\
\hline \multicolumn{6}{|c|}{ North Waziristan } \\
\hline Shewa & 966 & 29 & 35 & $3 \dagger$ & $3.62 \dagger$ \\
\hline Spinwam & 530 & 17 & 21 & $3.2 \dagger$ & $3.96 \dagger$ \\
\hline Mirali & 320 & 6 & 7 & 1.87 & 2.18 \\
\hline Edaky & 463 & 9 & 11 & 1.94 & 2.37 \\
\hline Darpakheil & 450 & 11 & 14 & 2.44 & $3.11 \dagger$ \\
\hline Hasankheil & 373 & 9 & 11 & 2.41 & 2.94 \\
\hline Dosali & 512 & 19 & 24 & $3.71 \dagger$ & $4.68 \dagger$ \\
\hline Miranshah & 455 & 15 & 17 & $3.29 \dagger$ & $3.73 \dagger$ \\
\hline Razmak & 367 & 14 & 16 & $3.81 \dagger$ & $4.35 \dagger$ \\
\hline Subtotal & 4,436 & 129 & 156 & 2.91 & $3.51 \dagger$ \\
\hline \multicolumn{6}{|c|}{ South Waziristan } \\
\hline Wanna & 412 & 14 & 28 & 3.39 & $6.79 \dagger$ \\
\hline Shekai & 463 & 12 & 18 & 2.59 & $3.88 \dagger$ \\
\hline Jandola & 516 & 10 & 10 & 1.93 & 1.93 \\
\hline Sra Roha & 253 & 8 & 11 & $3.16 \dagger$ & $4.34 \dagger$ \\
\hline Makeen & 169 & 4 & 9 & 2.36 & $5.32 \dagger$ \\
\hline Janata & 448 & 6 & 11 & 1.33 & 2.45 \\
\hline Sreykhoray & 195 & 6 & 12 & $3.07 \dagger$ & $6.15 \dagger$ \\
\hline Kotkai & 755 & 12 & 18 & 1.58 & 2.38 \\
\hline Subtotal & 3,112 & 72 & 117 & 2.3 & $3.75 \dagger$ \\
\hline Total & 7,548 & 201 & 273 & 2.66 & 3.61 \\
\hline
\end{tabular}

A leishmaniasis control committee should be established by health authorities in association with the Ministry of Health. It is strongly recommended that proper recordkeeping and documentation systems for leishmaniasis be initiated by health authorities at the local, provincial, and national levels and be well maintained to identify leishmaniasis outbreaks so that control measures can be started in time. Further, IDP camps must be monitored regularly to minimize the risk that nonendemic areas will be exposed to the disease by infected IDPs.

\section{Acknowledgment}

We thank Relief International, Pakistan, for providing funding for conducting this study on the prevalence of leishmaniasis in Waziristan, Pakistan.

This study was conducted in the following institutions: Vector Borne Diseases Management Center, Department of Microbiology, Kohat University of Science and Technology, Kohat, KP, Pakistan; ANSES-French Agency for Health and Safety, Animal Health Laboratory, Leishmaniasis and Sandflies Team, MaisonsAlfort, France; and US Naval Medical Research Unit (NAMRU3), Cairo, Egypt.

\section{About the Author}

Dr. Hussain is an associate professor and is in charge of the vector-borne diseases laboratory in the Department of Microbiology, Kohat University of Science and Technology, Khyber Pakhtunkhwa, Pakistan. His research interests include molecular characterization of Leishmania species in endemic areas of Pakistan.

\section{References}

1. Azizi K, Rassi Y, Javadian E, Motazedian MH, Rafizadeh S, Yaghoobi Ershadi MR, et al. Phlebotomus (Paraphlebotomus) alexandri: a probable vector of Leishmania infantum in Iran. Ann Trop Med Parasitol. 2006;100:63-8. http://dx.doi.org/10.1179/136485906X78454

2. Hussain M, Munir S, Jamal MA, Ayaz S, Akhoundi M, Mohamed K. Epidemic outbreak of anthroponotic cutaneous leishmaniasis in Kohat District, Khyber Pakhtunkhwa, Pakistan. Acta Trop. 2017;172:147-55. http://dx.doi.org/10.1016/ j.actatropica.2017.04.035

3. Kassi M, Kassi M, Afghan AK, Rehman R, Kasi PM. Marring leishmaniasis: the stigmatization and the impact of cutaneous leishmaniasis in Pakistan and Afghanistan. PLoS Negl Trop Dis. 2008;2:e259. http://dx.doi.org/10.1371/journal.pntd.0000259

4. Hussain M, Munir S, Ayaz S, Khattak BU, Khan TA, Muhammad N, et al. First report on molecular characterization of Leishmania species from cutaneous leishmaniasis patients in southern Khyber Pakhtunkhwa province of Pakistan. Asian Pac J Trop Med. 2017;10:718-21. http://dx.doi.org/10.1016/ j.apjtm.2017.07.015

5. Hayat M, Ahmad I, Afaq U, Munir S, Anees M, Hussain T, et al. Prevalence and molecular diagnosis of cutaneous leishmaniasis in local population of Dir District, Khyber Pakhtunkhwa, Pakistan. Int J Pharm Sci Rev Res. 2013;21:359-64.

6. Parvizi P, Mauricio I, Aransay AM, Miles MA, Ready PD. First detection of Leishmania major in peridomestic Phlebotomus papatasi from Isfahan province, Iran: comparison of nested PCR of nuclear ITS ribosomal DNA and semi-nested PCR of minicircle kinetoplast DNA. Acta Trop. 2005;93:75-83. http://dx.doi.org/ 10.1016/j.actatropica.2004.09.007

7. Ayaz S, Khan S, Khan SN, Shams S, Saqalain M, Ahmad J, et al. Cutaneous leishmaniasis in Karak, Pakistan: report of an outbreak and comparison of diagnostic techniques. African Journal of Biotechnology. 2011;10:9908-10. http://dx.doi.org/10.5897/ AJB10.1987 
8. Killick-Kendrick R, Killick-Kendrick M, Tang Y. Anthroponotic cutaneous leishmaniasis in Kabul, Afghanistan: the low susceptibility of Phlebotomus papatasi to Leishmania tropica. Trans R Soc Trop Med Hyg. 1994;88:252-3. http://dx.doi.org/ 10.1016/0035-9203(94)90320-4

9. Khan NH, Bari AU, Hashim R, Khan I, Muneer A, Shah A, et al. Cutaneous leishmaniasis in Khyber Pakhtunkhwa province of Pakistan: clinical diversity and species-level diagnosis. Am J Trop Med Hyg. 2016;95:1106-14. http://dx.doi.org/10.4269/ ajtmh.16-0343

10. van Thiel P-P, Leenstra T, de Vries HJ, van der Sluis A, van Gool T, Krull AC, et al. Cutaneous leishmaniasis (Leishmania major infection) in Dutch troops deployed in northern Afghanistan: epidemiology, clinical aspects, and treatment. Am J Trop Med Hyg. 2010;83:1295-300. http://dx.doi.org/10.4269/ajtmh.2010.10-0143

Address for correspondence: Shahzad Munir, Yunnan Agricultural University, Kunming 650201, China; email: shazid_10@yahoo.com

\section{Ocular Vaccinia Infection in Dairy Worker, Brazil}

\section{Maurício Teixeira Lima, Graziele Pereira Oliveira, Felipe Lopes Assis, Danilo Bretas de Oliveira, Sidiner Mesquita Vaz, Giliane de Souza Trindade, Jônatas Santos Abrahão, Erna Geessien Kroon}

\begin{abstract}
Author affiliation: Universidade Federal de Minas Gerais, Belo Horizonte, Brazil (M.T. Lima, G.P. Oliveira, F.L. Assis, D.B. de Oliveira, G. de Souza Trindade, J.S. Abrahão, E.G. Kroon); Casa de Caridade de Carangola, Carangola, Brazil (S.M. Vaz); Universidade Federal dos Vales do Jequitinhonha e Mucuri, Diamantina, Diamantina, Brazil (D.B. de Oliveira)
\end{abstract}

DOI: https://doi.org/10.3201/eid2401.170430

We studied a clinical case of vaccinia virus that caused an ocular manifestation in a dairy worker in Brazil. Biologic and molecular analyses identified a co-infection with 2 isolates from different Brazilian vaccinia virus phylogenetic groups.

$\mathrm{D}$ etection of co-infections for various viral pathogens recently has increased $(1,2)$. However, the presence of $\geq 2$ viral etiologic agents often is not considered (1). The range of pathogens that can present co-infections and the association of these infections with the occurrence and severity of disease remain unclear $(1,2)$. Vaccinia virus (VACV), the prototype virus of the genus Orthopoxvirus, has been associated with exanthematic outbreaks in Asia and South America that affect mainly dairy cattle and rural workers $(3,4)$. In Brazil, several Brazilian VACV (VACV-BR) have been isolated and characterized biologically and phylogenetically. These studies demonstrated that circulating viruses belonged to at least 2 distinct genetic clusters (48 ). Previous studies have demonstrated the co-circulation of distinct VACV isolates during the same outbreak and VACV co-infecting horses and cattle (6-8).

We obtained 2 distinct VACV isolates from the same clinical sample from 1 eye of a rural worker. Our data show that the eye was co-infected with 2 VACV and demonstrates the detection and isolation of VACV from a natural case of ocular vaccinia infection.

In September 2015, an unvaccinated 45-year-old man who worked on a farm in Carangola County, Minas Gerais State, Brazil $\left(20^{\circ} 44^{\prime} 06^{\prime \prime} \mathrm{S}, 42^{\circ} 01^{\prime} 52^{\prime \prime} \mathrm{W}\right)$, showed development of typical manifestations of vaccinia infection, including fever and painful vesiculopustular lesions (online Technical Appendix Figure, panel A, https://wwwnc.cdc. gov/EID/article/24/1/17-0430-Techapp1.pdf). He had lesions on the left hand, right arm, and nose and an atypical manifestation in the left eye with aches in the ocular globe and periorbital region. The clinical condition progressed to major visual acuity losses in the affected eye. He reported recent contact with sick cows on the farm during milking.

Dried swab specimens from his lesions were soaked in $200 \mu \mathrm{L}$ phosphate-buffered saline containing amphotericin B $(4 \mu \mathrm{g} / \mathrm{mL})$, penicillin $(200 \mathrm{U} / \mathrm{mL})$, and streptomycin $(100 \mu \mathrm{g} / \mathrm{mL})$; homogenized; and centrifuged at 3,000 $\times g$ for $5 \mathrm{~min}$ (4). The supernatants were used for molecular diagnosis using orthopoxvirus-specific PCR that targeted the C11R gene, which encodes viral growth factor, and the A56R gene, which encodes viral hemagglutinin protein (4). All samples were positive for both orthopoxvirus targets.

Vero cells were cultured in $25-\mathrm{cm}^{2}$ culture flasks and infected with the specimen supernatants to isolate the virus at $37^{\circ} \mathrm{C}$ until a cytopathic effect was detected (4). VACV was isolated from the hand, nose, and eye samples. These isolates were tested for their plaque phenotypes in BSC-40 cells incubated at $37^{\circ} \mathrm{C}$ for $48 \mathrm{~h}(4)$, which demonstrated the presence of at least 2 types of viral populations comprising small and large plaques in an estimated ratio 2:1. Two viral plaques (1 forming large and 1 forming small plaques) were obtained from the eye sample after 3 additional rounds of plaque purification in BSC-40 cells (online Technical Appendix Figure, panel B) (4). The viral plaques were propagated and titrated by plaque assay in Vero cells, and their DNA was extracted (4).

We obtained the complete genomes using the Illumina MiSeq instrument (Illumina, San Diego, CA, USA) with the paired-end application. The sequence reads were assembled de novo using ABYSS software (http://www.bcgsc.ca/platform/bioinfo/software/abyss), and the resulting contigs were ordered by the python-based CONTIGuator.py software (http://contiguator.sourceforge.net). The GenBank accession numbers are MG012795 (small) and MG012796 (large). 